\title{
MASS TRANSFER IN TWO- AND THREE-PHASE FLUIDIZED BEDS
}

\author{
S. K. CHANG, Y. KANG AND S. D. KIM \\ Department of Chemical Engineering, Korea Advanced Institute of Science \\ and Technology, Seoul, Korea 131
}

Key Words: $\quad$ Mass Transfer, Fluidized Beds, Three Phase, Bubble Column, Interfacial Area

\begin{abstract}
Mass transfer characteristics of two- (gas-liquid) and three-phase (gas-liquid-solid) fluidized beds in a $6.64 \mathrm{~cm}$ i.d. and $1.8 \mathrm{~m}$-high Plexiglas column have been determined in terms of gas-liquid mass transfer coefficient and interfacial area.

In three-phase fluidized beds, carbonate/bicarbonate buffer solution, carbon dioxide and glass beads of three sizes were used as the liquid, gas and solid phases, respectively.

The effects of liquid velocity $(5.4-13.0 \mathrm{~cm} / \mathrm{s})$, gas velocity $(1.0-6.5 \mathrm{~cm} / \mathrm{s})$, liquid-phase ionic strength $(0.5-3.0 \mathrm{~mol} / l)$ and particle size $(1.7-6.0 \mathrm{~mm})$ on the mass transfer coefficient and the interfacial area were determined.

The volumetric mass transfer coefficient, $k_{L} a$, and the gas/liquid interfacial area, $a$, increased with increasing gas velocity, particle size and liquid-phase ionic strength in three-phase fluidized beds.

The volumetric mass transfer coefficient and the gas-liquid interfacial area were correlated in terms of gas and liquid velocities and particle size. The liquid-side mass transfer coefficient, $\boldsymbol{k}_{L}$, was correlated by the Schmidt and modified Reynolds numbers in the two- and three-phase fluidized beds of 6 -mm particles based on the isotropic turbulence theory.
\end{abstract}

\section{Introduction}

Three-phase fluidized beds in which solid particles are fluidized by an upward cocurrent flow of gas and liquid are finding increased use in industrial processes. The principal application is for gas-liquid reactions in which catalyst is used to enhance the reactions. The Fisher-Tropsch process, coal liquefaction, the hydrogenation of liquid petroleum fractions, the hydrogenation of unsaturated fats and slurry methanation of carbon monoxide are examples of such processes.

The gas-liquid mass transfer can be affected by the presence of solids and it was found to be liquid-phase controlled in many cases for three-phase fluidized beds. ${ }^{1)}$ Therefore, the liquid-side mass transfer coefficient and the surface area are important parameters for the design of three-phase reactors.

The mass transfer coefficient has been characterized as a function of liquid and gas velocities and particle size. It has been found that the volumetric mass transfer coefficient increases with the gas flow rate. ${ }^{18)}$ However, the mass transfer coefficient mainly depends on the particle size ${ }^{17)}$ since the particle size is known to differentiate the bubble coalescing and disintegrating flow regimes in three-phase fluidized beds. ${ }^{11)}$ In addition, the bubble properties are known to be affected by the ionic strength and the surface

Received March 5, 1986. Correspondence concerning this article should be addressed to S. D. Kim. tension of the solutions in the bubble columns. ${ }^{22)}$

The objectives of this study are to provide data on the mass transfer coefficient and the surface area and to determine the effects of the liquid and gas velocities, the particle size and the ionic strength on the mass transfer coefficient and the surface area in twoand three-phase fluidized beds.

\section{Experimental}

Experiments were carried out in a $6.64 \mathrm{~cm}-i . d$. and $1.8 \mathrm{~m}$-high Plexiglas column, shown in Fig. 1. The main section of the column was constructed from two pieces of $6.64 \mathrm{~cm}$-i.d. $\times 90 \mathrm{~cm}$-high Plexiglas cylinder flanged together. The solid particles were supported on a perforated plate which contained 60 evenly spaced holes of $2 \mathrm{~mm}$ diameter and served as the liquid distributor. The grid was situated between the main column section and a $20 \mathrm{~cm}$-high $\times 6.64 \mathrm{~cm}$-i.d. stainless steel distributor box into which liquid was introduced through a $2.54-\mathrm{cm}$ pipe from a liquid reservoir. Its flow rate was measured with a calibrated rotameter and regulated by means of globe valves on the feed and bypass lines. The gas was introduced through a pressure regulator, a filter and a rotameter. It was admitted to the bed through three $6.0-\mathrm{mm}$ perforated feed pipes drilled with $1 \mathrm{~mm}$ holes in the grid. This arrangement allows the gas and the liquid to enter the bed separately.

Glass beads of $1.7,4.0$ or $6.0 \mathrm{~mm}$ diameter and a 


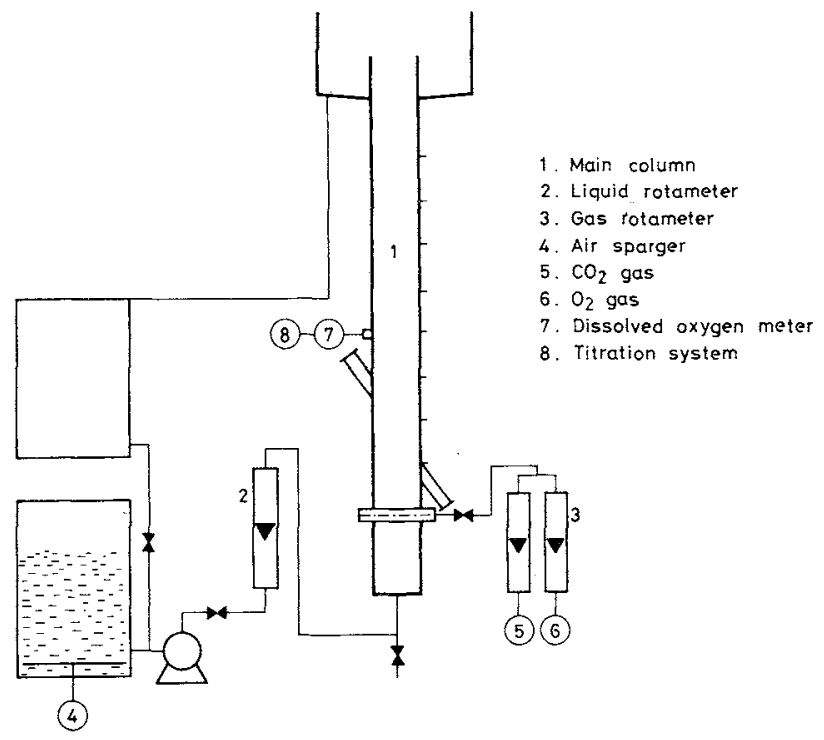

Fig. 1. Experimental apparatus.

density of $2.5 \mathrm{~g} / \mathrm{cm}^{3}$ were used. The mass weight of the particles was approximately $2.4 \mathrm{~kg}$. The ranges of superficial velocities of gas and liquid were $0.5-7.0$ and $5.4-13.0 \mathrm{~cm} / \mathrm{s}$, respectively.

The gas and the liquid were introduced into the bed of solids at desired superficial velocities. When steady state was reached, the pressure profile along the column height was measured using liquid manometers. Liquid samples were withdrawn $60 \mathrm{~cm}$ from the top of the distributor. The sampling bottle as a gas-liquid separator consisted of an upward-facing orifice, an incoming liquid flow inlet port and an outlet nozzle. The incoming liquid flow rate was controlled by a needle valve. The liquid sample was passed through a tube containing an oxygen probe (YSI Model 56) and was then collected for determination of carbonate/bicarbonate concentration.

\subsection{Determination of volumetric mass transfer coef- ficient and interfacial area}

The volumetric mass transfer coefficient, $k_{L} a$, and the interfacial area, $a$, were determined from the sample by means of simultaneous physical desorption of one gas and absorption with chemical reaction of another solute gas into the liquid phase. ${ }^{5,19)}$ The rate of desorption is used to calculate the volumetric mass transfer coefficient and the rate of absorption with chemical reaction is used to evaluate the interfacial area. Using this method, the volumetric mass transfer coefficient and the interfacial area can be determined under identical hydrodynamic and physico-chemical conditions. $^{5)}$

The rate of absorption in a fast pseudo first-order reaction in the liquid phase can be given by ${ }^{4)}$

$$
R_{\mathrm{A}} a=a C_{\mathrm{A}}^{*}\left(k_{L \mathrm{~A}}^{2}+D_{\mathrm{A}} k_{2} C_{o}\right)^{1 / 2}
$$

The rate of physical desorption of oxygen can be given as

$$
R_{\mathrm{B}} a=k_{L \mathrm{~B}} a \Delta C_{\mathrm{B}, m}
$$

in which $\Delta C_{\mathrm{B}, m}$ is the logarithmic mean value of the difference in oxygen concentration between the interface and the bulk of the liquid phase. Since the true mass transfer coefficient is proportional to the square root of the diffusivity, ${ }^{5}$ the desorption rate coefficient can be expressed as

$$
k_{L \mathrm{~B}}=k_{L \mathrm{~A}} \sqrt{D_{\mathrm{B}} / D_{\mathrm{A}}}
$$

Substituting Eq. (3) into Eq. (2), we have the rate of desorption:

$$
R_{\mathrm{B}} a=k_{\mathrm{LA}} a \sqrt{D_{\mathrm{B}} / D_{\mathrm{A}} C_{\mathrm{B}, m}}
$$

The interfacial area, $a$, can be determined from Eqs. (1)-(4) as

$$
a=\left\{\left(R_{\mathrm{A}} a / C_{\mathrm{A}}^{*}\right)^{2}-\left(k_{L \mathrm{~A}} a\right)^{2} / D_{\mathrm{A}} k_{2} C_{o}\right\}^{1 / 2}
$$

where $R_{\mathrm{A}} a$ and $R_{\mathrm{B}} a$ are determined from experimental measurement and subscripts $\mathrm{A}$ and $\mathrm{B}$ refer to the absorption of $\mathrm{CO}_{2}$ and the desorption of oxygen, respectively.

From Eq. (5), the true mass transfer coefficient, $K_{L}$, can be derived in Eq. (6) with the assumption that the gas phase resistance is negligibly small.

$$
k_{L}=K_{L}=\left(K_{L} a\right) / a
$$

For the physical absorption system, tap water as liquid phase and a mixture of $80 \% \mathrm{CO}_{2}$ and $20 \% \mathrm{~N}_{2}$ as gas phase were employed.

For the present chemical absorption system, $0.125 \mathrm{~mol} / \mathrm{l}$ sodium carbonate/sodium bicarbonate solution with a buffer ratio of 1.0 containing $\mathrm{NaCl}$ solution in the range $0.5-2.5 \mathrm{~mol} / /$ as the liquid phase was used in order to vary the ionic strength without changing the viscosity and the diffusivity appreciably, and $100 \% \mathrm{CO}_{2}$ was employed as the gas phase.

The ionic strength, $I$, has been defined as

$$
I=\frac{1}{2} \sum m_{i} Z_{i}^{2}
$$

where $m_{i}$ and $Z_{i}$ are the molality and ionic charge, respectively.

The viscosity and density were determined by using an Ostwald capillary viscometer and a hydrometer, respectively.

The diffusivities of $\mathrm{CO}_{2}$ and $\mathrm{O}_{2}$ gases in the ionic solution were determined by the Stokes-Einstein equation. To maintain constant solubilities of $\mathrm{CO}_{2}$ and $\mathrm{O}_{2}$ in the liquid, the liquid temperature was maintained at $(20 \pm 2)^{\circ} \mathrm{C}$.

The properties of the liquids and diffusivities of gases are shown in Table $\mathbf{1}$. 
Table 1. Properties of liquids and gases

\begin{tabular}{|c|c|c|c|c|c|}
\hline Solutions & 1 & 2 & 3 & 4 & 5 \\
\hline $\mathrm{Na}_{2} \mathrm{CO}_{3} \quad[\mathrm{~mol} / \mathrm{l}]$ & - & 0.125 & 0.125 & 0.125 & 0.125 \\
\hline $\mathrm{NaHCO}_{3}[\mathrm{~mol} / \mathrm{l}]$ & - & 0.125 & 0.125 & 0.125 & 0.125 \\
\hline $\mathrm{NaCl} \quad[\mathrm{mol} / l]$ & - & - & 0.500 & 1.500 & 2.500 \\
\hline Viscosity $[\mathrm{mPa} \cdot \mathrm{s}]$ & 1.01 & 1.071 & 1.077 & 1.159 & 1.269 \\
\hline $\begin{array}{l}\mathrm{CO}_{2} \text { Diffusivity } \\
\quad\left[\times 10^{-5} \mathrm{~cm}^{2} / \mathrm{s}\right]\end{array}$ & 1.70 & 1.603 & 1.594 & 1.481 & 1.353 \\
\hline $\begin{array}{l}\mathrm{O}_{2} \text { Diffusivity } \\
\quad\left[\times 10^{-5} \mathrm{~cm}^{2} / \mathrm{s}\right]\end{array}$ & 2.10 & 1.98 & 1.97 & 1.83 & 1.67 \\
\hline $\begin{array}{l}\text { Ionic strength } \\
\qquad[\mathrm{mol} / l]\end{array}$ & 0.00 & 0.500 & 1.000 & 2.000 & 3.000 \\
\hline
\end{tabular}

\section{Results and Discussion}

In bubble columns and three-phase fluidized beds, the liquid-phase flow has been assumed as plug flow ${ }^{1,5,14,15)}$ since the liquid mixing in three-phase fluidized beds was found to be insignificant in beds of large particle size $\left(d_{p}>3 \mathrm{~mm}\right)$ and column diameter less than $15 \mathrm{~cm} .^{6,10,13)}$ These conditions were satisfied in the beds of $4.0-$ and $6.0-\mathrm{mm}$ glass beads. Also, it was reported that the liquid mixing in beds of 1.7 - and $2.0-\mathrm{mm}$ particles was small ${ }^{6,10)}$ and that the volumetric mass transfer coefficient with and without allowance for liquid mixing showed no significant error when the effect of liquid mixing was ignored. ${ }^{5)}$ Thus, the volumetric mass transfer coefficients were calculated from Eq. (2) using the logarithmic mean value of the concentration difference in the liquid phase. The interfacial area, $a$, and the true mass transfer coefficient, $k_{L}$, were calculated from Eqs. (5) and (6), respectively.

\subsection{Volumetric mass transfer coefficient and inter- facial area}

The experimental values of $k_{L} a$ in the bubble columns and three-phase fluidized beds of $1.7-\mathrm{mm}$, $4.0-\mathrm{mm}$ and $6.0-\mathrm{mm}$ glass beads as a function of gas and liquid velocity are shown in Fig. 2. The superficial gas velocity of carbon dioxide was calculated as the arithmetic mean velocity at the inlet and the outlet.

As can be seen in the figure, $k_{L} a$ in the bubble column increases with gas velocity. However, the effect of liquid velocity on $k_{L} a$ was marginal. The present liquid velocity range did not affect bubble coalescence to any appreciable degree. But the mass transfer coefficient increased due to the presence of larger bubbles generated by increased coalescence with increasing gas velocity. Lamont and $\mathrm{Scott}^{13)}$ suggested that the gas/liquid mass transfer rate is mainly controlled by the small-scale eddies in the turbulent field. The mass transfer resistance in the gas film of bubbles may be small since the diffusion coefficient is very large. ${ }^{7)}$ Therefore, the mass transfer coefficient may increase with the increase in gas-liquid contact by turbulence.
The three-phase fluidized bed may be composed of three different functional regions, namely the fluidized, wake, and gas bubble regions. ${ }^{2)}$ The wake region may contain a turbulent liquid movement which may produce microscale eddies since the rising bubbles are trailed by turbulent wakes which cocurrently form and separate during their rise in the bed. The solid content in the wake is found to be far smaller than that in the fluidized region, ${ }^{2}$ whereas the fluidized region contains solid particles and liquid. The volume fraction of the fluidized region, $\varepsilon_{f}$, has been determined. ${ }^{8)}$ The obtained values of $\varepsilon_{f}$ are shown in Table 2. The amount of bubble-driven turbulent liquid in the wake region and the gas bubble region increased with gas velocity, consequently resulting in the increase of gas/liquid interfacial area and volumetric mass transfer coefficient in threephase fluidized beds.

The volumetric mass transfer coefficients in the beds of $4.0-$ and $6.0-\mathrm{mm}$ glass beads exhibit higher values than those in the bubble columns (Fig. 2). However, a reverse trend was observed in the bed of $1.7-\mathrm{mm}$ glass beads. Also, the gas/liquid interfacial area in the bed of $1.7-\mathrm{mm}$ particles was smaller than that in bubble columns (Fig. 2).

The effect of particle size on $k_{L} a$ and $a$ can be seen in Fig. 3, in which the results of previous studies ${ }^{5,14)}$ are also included.

In three-phase fluidized beds, it is known that the smaller particles $\left(d_{p}<2.5 \mathrm{~mm}\right)$ provide bubble coalescence while the larger particles $\left(d_{p}>2.5 \mathrm{~mm}\right)$ disintegrate bubbles. ${ }^{11)}$ Therefore, gas-phase holdup in the bed of $1.7-\mathrm{mm}$ glass beads is comparatively smaller than that in bubble columns. This may imply that $k_{L} a$ and $a$ in the bed of $1.7-\mathrm{mm}$ particles are smaller than the values in bubble columns. In contrast, in the beds of larger particles, both $k_{L} a$ and $a$ increased with particle size due to an increase in bubble breaking $^{12,13)}$ and a consequent increase in the gas-phase holdup in the bed.

The effect of liquid velocity on $k_{L} a$ and $a$ was relatively small compared to the effects of gas velocity and particle size, as previously reported., ${ }^{919}$ However, $k_{L} a$ and $a$ exhibit maximum values with the variation of liquid velocity in the beds of 4.0- and 6.0$\mathrm{mm}$ particles as shown in Fig. 4. The same trend has been reported previously, as shown in Fig. $4 .^{5,16)}$ In the lower range of liquid velocities, an increase in liquid velocity might promote bed turbulence in threephase fluidized beds so that the particle motion becomes more effective in breaking the rising bubbles with increasing liquid velocity. Therefore, the interfacial area, $a$, increased due to the decrease in bubble size and its rising velocity. However, in the higher liquid velocity range, the liquid element velocity and the fluctuation of solids might decrease 
Table 2. Volume fraction of fluidized region

\begin{tabular}{cccc}
\hline$d_{p}[\mathrm{~mm}]$ & $\mu_{i}[\mathrm{mPa} \cdot \mathrm{s}]$ & $U_{s}[\mathrm{~cm} / \mathrm{s}]$ & $\varepsilon_{f}$ \\
\hline 1.7 & 1.07 & 3.0 & 0.86 \\
1.7 & 1.07 & 6.5 & 0.84 \\
4.0 & 1.07 & 3.0 & 0.81 \\
4.0 & 1.07 & 5.0 & 0.79 \\
6.0 & 1.07 & 3.0 & 0.74 \\
\hline
\end{tabular}

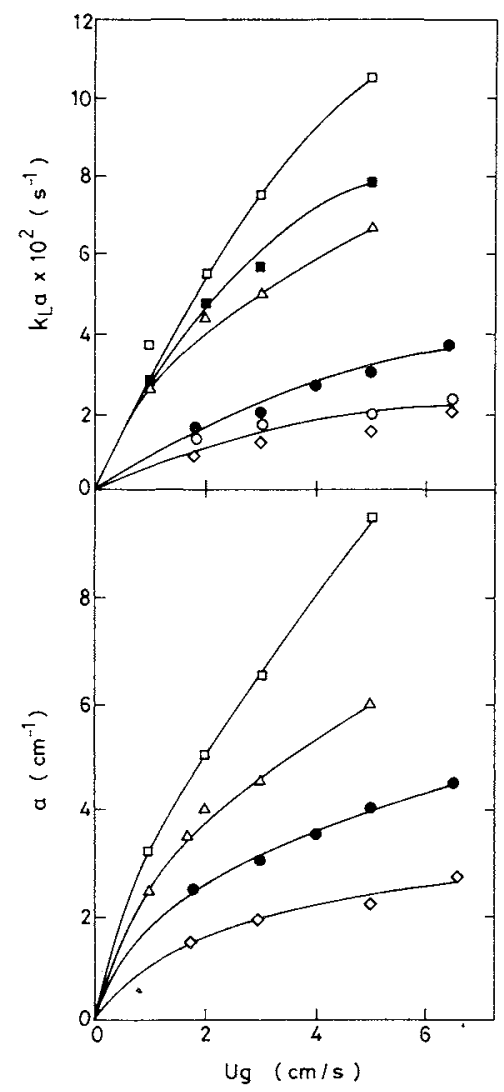

Fig. 2. Effect of $U_{g}$ on $k_{L} a$ and $a$ in bubble columns and three-phase fluidized beds.

$\begin{array}{lcccccc} & \bullet & \diamond & 0 & \triangle & \square & \square \\ d_{p}(\mathrm{~mm}): & 0.0 & 1.7 & 1.7 & 4.0 & 4.0 & 6.0 \\ U_{1}(\mathrm{~cm} / \mathrm{s}): & 8.0 & 6.4 & 8.0 & 8.0 & 10.0 & 10.0\end{array}$

with increasing liquid velocity due to the decrease of hindrance effect of solids on the liquid element and the decrease of solids concentration. Moreover, an increase in liquid velocity gives rise to a higher bubble rising velocity, which results in the decrease of gasphase holdup and the interfacial area. In consequence, $k_{L} a$ and $a$ decreased with increasing liquid velocity in the higher liquid velocity range.

The decrease of gas-phase holdup with increasing liquid velocity was observed in previous studies. ${ }^{5,12,14)}$ There are two conflicting effects, namely, the increase of turbulence and the decrease of solid holdup in the bed with increasing liquid velocity. The former may dominate in the lower liquid velocity range and the latter in the higher liquid velocity range. As a result of these two conflicting effects, the gas-phase holdup

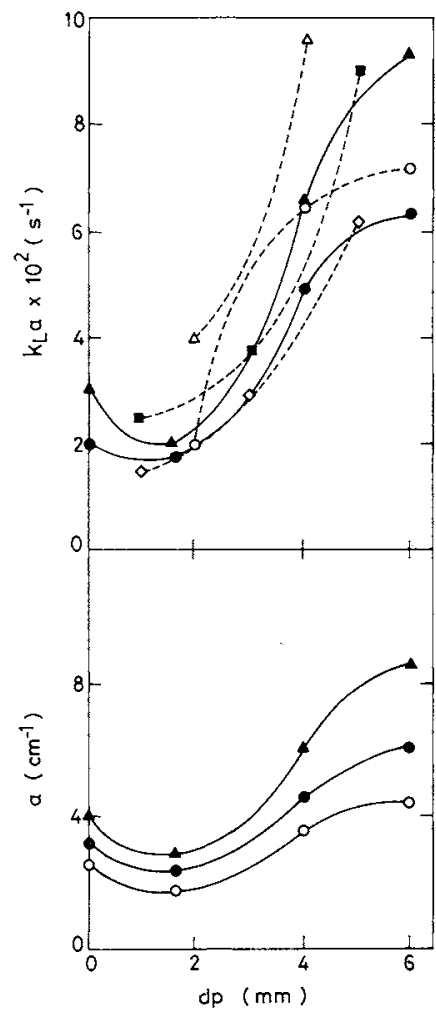

Fig. 3. Effect of $d_{p}$ on $k_{L} a$ and $a$ in three-phase fluidized beds.

$$
\begin{aligned}
& \begin{array}{cccccccc} 
& 0 & \bullet & \Delta & 0 & \Delta & \diamond & \boldsymbol{0} \\
U_{1}(\mathrm{~cm} / \mathrm{s}): & 8.0 & 8.0 & 8.0 & 10.0 & 10.0 & 10.0 & 10.0
\end{array} \\
& \begin{array}{llllrrrr}
U_{y}(\mathrm{~cm} / \mathrm{s}): & 1.8 & 3.0 & 5.0 & 3.0 & 5.0 & 3.0 & 5.0
\end{array} \\
& \text { This study Dhanuka \& Nguyen-Tien } \\
& \text { Stepanek (5) et al. (16) }
\end{aligned}
$$

increases or decreases slightly with liquid velocity. Thus, the minor effect of the liquid velocity on $k_{L} a$ and $a$ may be due to a slight variation in the gas-phase holdup with the liquid velocity. In contrast, in the bed of $1.7-\mathrm{mm}$ glass beads, an increase in the liquid velocity may lead to an increase of turbulence and a consequent increase in $k_{L} a$ and $a$. Similar results have been reported by Dhanuka and Stepanek ${ }^{5)}$ in beds of $1.98-\mathrm{mm}$ glass beads, as shown in Fig. 4.

The effect of ionic strength of liquid on $k_{L} a$ and $a$ in three-phase fluidized beds is shown in Fig. 5. The $k_{L} a$ and $a$ values increased with increasing ionic strength in the beds of solids of all three sizes. This may be due to the decrease of bubble size with ionic strength since bubble coalescence can be inhibited by increasing the ionic strength. ${ }^{9,22)}$ The inhibition of bubble coalescence may be a result of the repulsive forces generated by the electrically charged liquid surface around the bubbles. However, this inhibition effect may be less effective in the beds of larger particles since the larger bubbles have an inertia force which may predominate the repulsive force between the bubbles in the bed. It is known that bubbles larger than $2.5 \mathrm{~mm}$ exhibit a free surface motion while smaller bubbles behave as rigid spheres. ${ }^{3)}$ Therefore, in the beds of larger bub- 


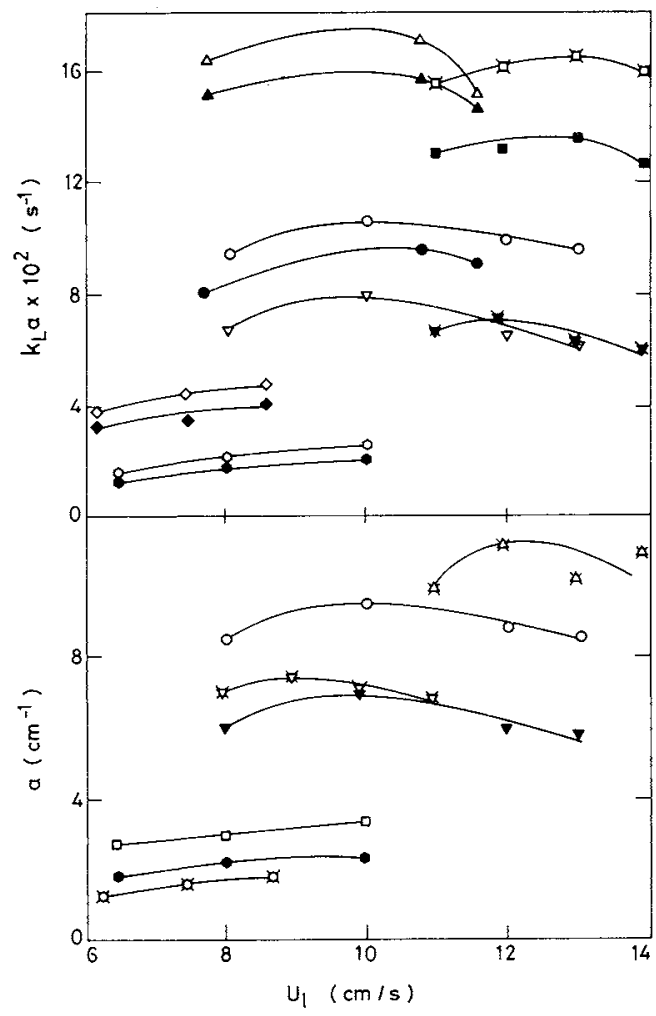

Fig. 4. Effect of $U_{l}$ on $k_{L} a$ and $a$ in three-phase fluidized beds.

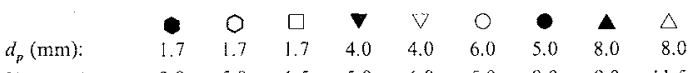

$$
\begin{aligned}
& l_{i,}(\mathrm{~cm} / \mathrm{s}): \quad \begin{array}{llllllllll}
3.0 & 5.0 & 6.5 & 5.0 & 6.0 & 5.0 & 8.0 & 9.0 & 11.5
\end{array} \\
& \text { This study } \underbrace{0.0}_{\text {Nguyen-Tien }} \\
& \text { et al. (16) }
\end{aligned}
$$

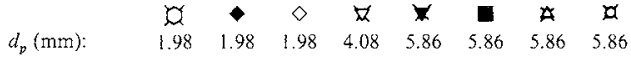

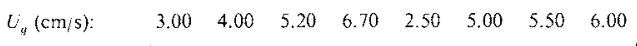

bles $\left(d_{p}=1.7 \mathrm{~mm}\right), k_{L} a$ and $a$ increased only slightly with ionic strength compared to that in the beds of smaller bubbles $\left(d_{p}=4.0\right.$ and $\left.6.0 \mathrm{~mm}\right)$, as shown in Fig. 5.

\subsection{Liquid-side mass transfer coefficient}

The effect of gas velocity on the liquid-side mass transfer coefficient, $k_{L}$, is shown in Fig. $\mathbf{6}$ as a function of liquid velocity and particle size. The value of $k_{L}$ in the bed of $1.7-\mathrm{mm}$ glass beads increased slightly with gas velocity as in the previous studies. ${ }^{5,17)}$ Increasing gas velocity resulted in bubble coalescence and this led to an increase in $k_{L}$ due to the free motion of the gas-liquid interface of larger bubbles. ${ }^{5)}$ However, in the beds of 4.0 - and $6.0-\mathrm{mm}$ particles, $k_{L}$ was nearly independent of gas and liquid velocities (Figs. 6B and 6C).

The ideal mean bubble diameter can be calculated from a knowledge of the gas-phase holdup and the gas-liquid interfacial area as

$$
d=6 \frac{\varepsilon_{g}}{a}
$$

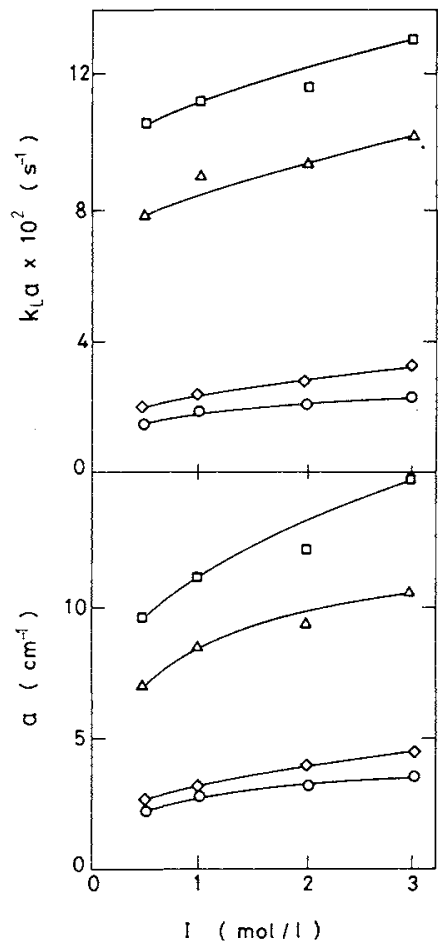

Fig. 5. Effects of $l$ on $K_{L} a$ and $a$ in three-phase fluidized beds.

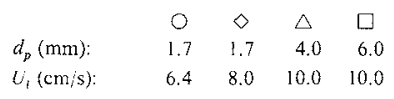

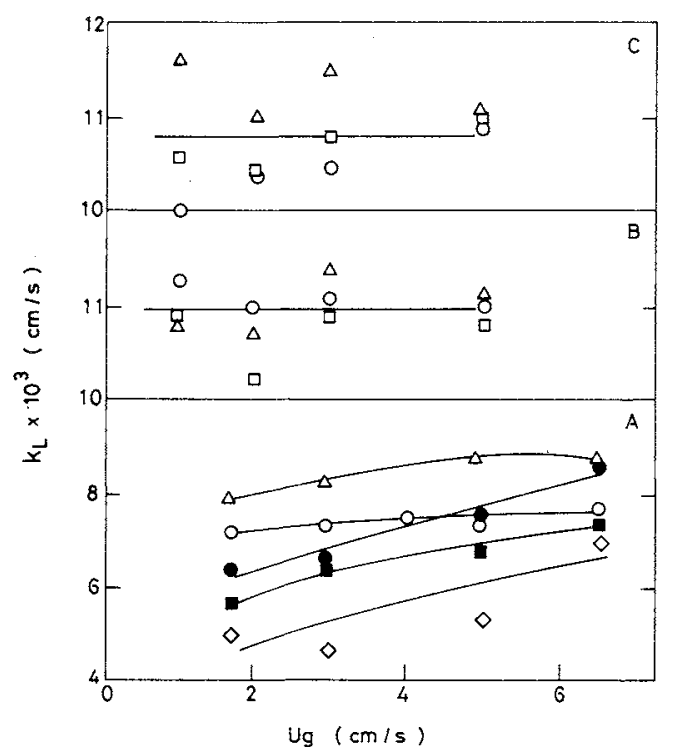

Fig. 6. Effect of $U_{g}$ on $k_{L}$ in three-phase fluidized beds.

$$
\begin{array}{lllllll}
\text { A: } d_{p}=1.7 \mathrm{~mm} & \text { B: } d_{p}=4.0 \mathrm{~mm} & \text { C: } d_{p}=6.0 \mathrm{~mm} & \\
U_{t}(\mathrm{~cm} / \mathrm{s}): & 5.4 & 6.4 & 8.0 & 10.0 & 8.0 & 12.0 \\
& \diamond & \square & 0 & \triangle & \bullet & \square
\end{array}
$$

The mean bubble diameters obtained were 1.3$1.6 \mathrm{~mm}$ in the beds of $4.0-\mathrm{mm}$ particles and $0.7-$ $1.0 \mathrm{~mm}$ in the bed of $6.0-\mathrm{mm}$ particles. The mean bubble diameters in the beds of 4.08 - and $5.86-\mathrm{mm}$ particles of Dhanuka and Stepanek ${ }^{5)}$ were 1.8-2.0 and $1.2-1.4 \mathrm{~mm}$, respectively. Since the value of $k_{L}$ in- 
creases with bubble diameter in beds of smaller bubbles less than $2 \mathrm{~mm}$, the present values of $k_{L}$ exhibited somewhat lower values than those of their study.

From the concept of surface renewal theory, ${ }^{4)}$ eddies with high energy may be responsible for the increase in the surface renewal rate in gas-liquid contact and the consequent increase in $k_{L}$ based on the following Eq. (9):

$$
k_{L}=D^{1 / 2} S^{1 / 2}
$$

where $D$ and $S$ are the molecular diffusivity and the surface renewal rate, respectively.

The net surface renewal rate may not change appreciably with the variation of gas and liquid velocities (Fig. 6). The increase in gas and liquid velocities enhances the velocity of liquid element. However, it reduces the residence time and the frequency of the eddies in the bed since the drag force on the eddies increases and the solid holdup decreases with the gas and liquid velocities.

In the beds of $1.7-\mathrm{mm}$ particles, the hindrance effect of solid particles may be small. $\left.{ }^{8}\right)$ Therefore, $k_{L}$ increased slightly with increasing gas and liquid velocities (Fig. 6A).

The effect of ionic strength, $I$, on $k_{L}$ is shown in Fig. 7. As can be seen, $k_{L}$ decreased with $I$. However, in the beds of $1.7-\mathrm{mm}$ particles, $k_{L}$ decreased slightly with increase in $I$. This decrease of $k_{L}$ may come from the inhibition of bubble coalescence from the ionic solutions. In the beds of $1.7-\mathrm{mm}$ particles, the inhibition effect of $I$ on bubble coalescence was found to be small as a result of the inertial force of larger bubbles. Thus, the variation of $k_{L}$ with ionic strength of the liquid phase was small.

\subsection{Correlations of data}

The $k_{L} a, a$ and $k_{L}$ data of the present and previous studies $^{5,18)}$ were correlated with the experimental variables from a least squares analysis. However, as seen in Fig. $4, k_{L} a$ and $a$ exhibited maximum values with variation in liquid velocity. Therefore, the present correlations shown below could not represent the general trend of $k_{L} a$ and $a$ values with liquid velocity. But it represents well the values of $k_{L} a$ and $a$ within $10 \%$ error as

$$
\begin{gathered}
k_{L} a=0.9 \times 10^{-3} U_{g}^{0.68} U_{l}^{0.63} d_{p}^{1.21} \\
\text { Correlation coefficient }=0.90 \\
a=0.19 U_{g}^{0.35} U_{l}^{0.85} d_{p}^{0.88} \\
\text { Correlation coefficient }=0.90
\end{gathered}
$$

where the units of $U_{g}$ and $U_{l}, d_{p}, k_{L} a$ and $a$ are $\mathrm{cm} / \mathrm{s}$, $\mathrm{mm}, 1 / \mathrm{s}$ and $1 / \mathrm{cm}$, respectively.

It has been found that $k_{L} a$ is proportional to Schmidt number $(S c)$ in beds of larger bubbles $\left(d_{b}>2.5 \mathrm{~mm}\right)$. But, in beds of smaller bubbles

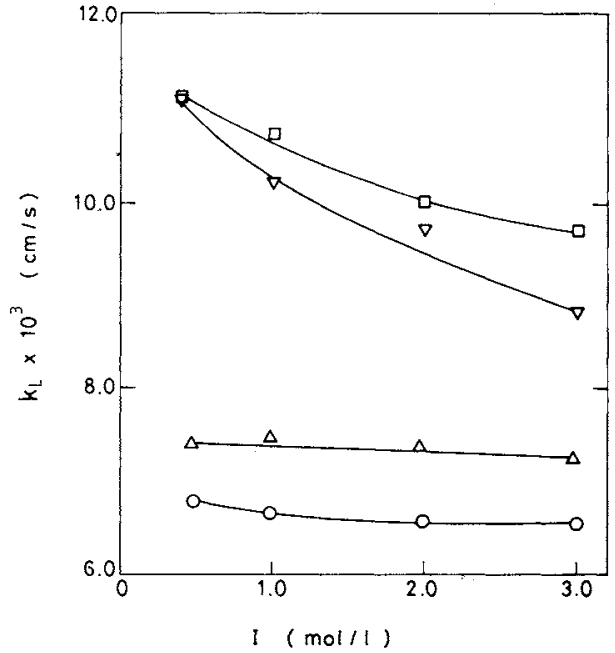

Fig. 7. Effect of $I$ on $k_{l}$ in three-phase fluidized beds $\left(U_{s}=5.0 \mathrm{~cm} / \mathrm{s}\right)$.

$\begin{array}{lcccc} & \bigcirc & \Delta & \square & \nabla \\ d_{p}(\mathrm{~mm}): & 1.7 & 1.7 & 4.0 & 6.0 \\ U_{1}(\mathrm{~cm} / \mathrm{s}): & 6.4 & 8.0 & 10.0 & 10.0\end{array}$

$\left(d_{b}<1 \mathrm{~mm}\right)$ which behave as rigid spheres, $k_{L} a$ is proportional to $S c^{2 / 313)}$

Since $k_{L}$ is strongly influenced by the velocity of liquid elements and eddies, $k_{L}$ can be represented by

$$
k_{L}=(S c)^{m}\left(R e_{p}\right)^{n}
$$

where $S c$ and $R e_{p}$ are Schmidt and particle Reynolds numbers, respectively. The particle Reynolds number has been related to the energy dissipation rate in the beds based on Kolmogoroff's local isotropic turbulence theory. ${ }^{20,21)}$

The energy dissipation rate of the liquid phase can be calculated from a knowledge of individual phase holdups, fluid properties and fluid velocities as

$$
E_{D}=\frac{\left(U_{l}+U_{g}\right)\left(\varepsilon_{g} \rho_{g}+\varepsilon_{l} \rho_{l}+\varepsilon_{s} \rho_{s}\right) g}{\varepsilon_{l} \rho_{l}}
$$

Since gas-liquid contact occurs through dispersed bubbles in three-phase fluidized beds, the particle Reynolds number can be replaced by the Reynolds number based on the mean bubble diameter as

$$
\frac{k_{L} d_{b}}{D}=\alpha(S c)^{m}\left(R e_{b}\right)^{n}
$$

where $m$ and $n$ are correlation constants which can be determined from the present experimental data in bubble columns and three-phase fluidized beds of 6mm particles.

For bubble column:

$$
S h=0.43(S c)^{1 / 2}\left(\frac{E_{D} d_{b}^{4}}{v^{3}}\right)
$$

Correlation coefficient $=0.86$

For three-phase fluidized bed of 6.0-mm particles: 


$$
S h=0.68(S c)^{1 / 2}\left(\frac{E_{D} d_{b}^{4}}{v^{3}}\right)
$$

Correlation coefficient $=0.87$

\section{Conclusions}

Volumetric mass transfer coefficient, $k_{L} a$, and interfacial area, $a$, increased with increasing gas velocity, particle size and ionic strength of the liquid in three-phase fluidized beds, whereas the values of $k_{L} a$ and $a$ exhibit a maximum value with increasing liquid velocity. However, in general, the effect of liquid velocity on $k_{L} a$ and $a$ was small.

In bubble columns, $k_{L} a$ and $a$ were smaller than in three-phase fluidized beds of $4.0-$ and $6.0-\mathrm{mm}$ particles. However, a reverse trend was observed in beds of $1.7-\mathrm{mm}$ particles.

The liquid-side mass transfer coefficient was correlated in terms of Sherwood number with Schmidt and modified Reynolds numbers based on the isotropic turbulence theory.

\section{Acknowledgement}

The authors wish to acknowledge a Grant-in-Aid for research from the Korea Science and Engineering Foundation.

\begin{tabular}{|c|c|c|}
\hline \multicolumn{3}{|c|}{ Nomenclature } \\
\hline$a$ & $=$ gas/liquid interfacial area & {$[1 / \mathrm{cm}]$} \\
\hline$\Delta C_{m}$ & $=$ logarithmic mean of concentration differe & {$[\mathrm{mol} / l]$} \\
\hline$C^{*}$ & $=$ saturation concentration & {$[\mathrm{mol} / \mathrm{l}]$} \\
\hline $\mathrm{Co}$ & $=$ reactant concentration in the bulk liquid & {$[\mathrm{mol} / \mathrm{l}]$} \\
\hline$D$ & $=$ molecular diffusivity & {$\left[\mathrm{cm}^{2} / \mathrm{s}\right]$} \\
\hline$d_{b}$ & $=$ bubblè diameter & [cm] \\
\hline$d_{p}$ & $=$ particle diameter & {$[\mathrm{cm}]$} \\
\hline$E_{D}$ & $\begin{array}{l}=\text { energy dissipation rate per unit mass } \\
\text { of liquid phase }\end{array}$ & {$\left[\mathrm{cm}^{2} / \mathrm{s}^{3}\right]$} \\
\hline$g$ & $=$ acceleration due to gravity & {$\left[\mathrm{cm} / \mathrm{s}^{2}\right]$} \\
\hline$I$ & $=$ ionic strength of liquid phase & {$[\mathrm{mol} / /]$} \\
\hline$K_{L}$ & $\begin{aligned}= & \text { overall mass transfer coefficient based } \\
& \text { on liquid side }\end{aligned}$ & {$[\mathrm{cm} / \mathrm{s}]$} \\
\hline$k_{2}$ & $=$ second-order rate constant & {$[l / \mathrm{mol} \cdot \mathrm{s}]$} \\
\hline$k_{L}$ & $=$ liquid-side mass transfer coefficient & {$[\mathrm{cm} / \mathrm{s}]$} \\
\hline$k_{L} a$ & $\begin{aligned}= & \text { volumetric gas/liquid mass transfer } \\
& \text { coefficient }\end{aligned}$ & {$[1 / \mathrm{s}]$} \\
\hline$m$ & $=$ constant & {$[-]$} \\
\hline$m_{i}$ & $=$ molality & {$[\mathrm{mol} / \mathrm{l}]$} \\
\hline$n$ & $=$ constant & {$[-]$} \\
\hline$R$ & $=$ absorption rate per unit surface area & $\left.\mathrm{nol} / \mathrm{cm}^{2} \mathrm{~s}\right]$ \\
\hline$R e_{b}$ & $\begin{aligned}= & \text { Reynolds number based on bubble diam } \\
& E_{D} d_{b}^{4} / v^{3}\end{aligned}$ & eter, \\
\hline$R e_{p}$ & $\begin{aligned}= & \text { Reynolds number based on particle diam } \\
& E_{D} d_{b}^{4} / v^{3}\end{aligned}$ & {$[-]$} \\
\hline$S$ & $=$ surface renewal rate & {$[1 / \mathrm{s}]$} \\
\hline
\end{tabular}

\begin{tabular}{|c|c|c|}
\hline$S c$ & $=$ Schmidt number, $v / D$ & {$[-$} \\
\hline$S h$ & $=$ Sherwood number, $k_{L} d_{b} / D$ & [- \\
\hline$U$ & $=$ fluid velocity & {$[\mathrm{cm}$} \\
\hline$Z_{i}$ & $=$ ionic charges & {[} \\
\hline$\alpha$ & $=$ constant & \\
\hline$\varepsilon$ & $=$ phase holdup & \\
\hline$\rho$ & $=$ density & {$[\mathrm{g} / \mathrm{cn}$} \\
\hline$y$ & $=$ kinematic viscosity & {$\left[\mathrm{cm}^{2}\right.$} \\
\hline$\mu$ & $=$ viscosity & \\
\hline
\end{tabular}

〈Subscripts〉

\begin{tabular}{|c|c|}
\hline & $=$ absorbed species \\
\hline & $=$ desorbed species \\
\hline & $=$ bubble \\
\hline f & $=$ fluidized region \\
\hline & $=$ gas \\
\hline & $=$ liquid \\
\hline & $=$ particle \\
\hline & $=$ solid \\
\hline
\end{tabular}

\section{Literature Cited}

1) Alvarez-Cuenca, M. and M. A. Nerenberg: Can. J. Chem. Eng., 59, 739 (1981).

2) Bahatia, V. K. and N. Epstein: "Fluidization and Its Applications," p. 380, Cepadues Eds. (1974).

3) Calderbank, P. H.: Chem. Engr., 212, CE 209 (1967).

4) Dankwerts, P. V.: Ind. Eng. Chem., 43, 1460 (1951).

5) Dhanuka, V. R. and J. B. Stepanek: AIChE J., 26, 1029 (1980).

6) El-Temtamy, S. A., Y. O. El-Sharnoubi and M. M. ElHalwagi: Chem. Eng. J., 18, 151 (1979).

7) Heijnen, J. J. and K. van't Riet: Chem. Eng. J., 28, 2I (1984).

8) Kang, Y. and S. D. Kim: Ind. Eng. Chem. Process Des. Dev., 25, 717 (1986).

9) Keitel, G. and U. Onken: Chem. Eng. Sci., 37, 1635 (1982).

10) Kim, S. D. and C. H. Kim: J. Chem. Eng. Japan, 16, 172 (1983).

11) Kim, S. D., C. G. J. Baker and M. A. Bergougnou: Can. J. Chem. Eng., 53, 134 (1975).

12) Kim, S. D., C. G. J. Baker and M. A. Bergougnou: Can. J. Chem. Eng., 50, 695 (1972).

13) Lamont, J. C. and D. S. Scott: AIChE J., 16, 513 (1970).

14) Lee, J. C. and H. Worthington: "Fluidization and its Applications," p. 407, Cepadues Eds. (1974).

15) Michelson, M. L. and K. Ostergaard: Chem. Eng. J., 1, 37 (1970).

16) Nguyen-Tien, K., A. N. Patwari, A. Schumpe and W. D. Deckwer: AIChE J., 31, 194 (1985).

17) Ostergaard, K.: AIChE Symp. Ser., 74, 82 (1978).

18) Ostergaard, K. and P. Fosbol: Chem. Eng. J., 3, 105 (1972).

19) Robinson, C. W. and C. R. Wilke: AIChE J., 20, 285 (1974).

20) Sanger, P. and W. D. Deckwer: Chem. Eng. J., 22, 179 (1981).

21) Suh, I. S., G. T. Jin and S. D. Kim: Int. J. Multiphase Flow, 11, 255 (1985).

22) Zieminski, S. A. and R. C. Whittermore: Chem. Eng. Sci., 26, 509 (1971). 